\title{
Strength Development of Fine Grained Mortar Containing Palm Oil Fuel Ash as a Partial Cement Replacement
}

\author{
Wan Yuslinda Wan Yusof *, Suraya Hani Adnan, Zalipah Jamellodin \\ and Noor Shuhada Mohammad \\ Universiti Tun Hussein Onn Malaysia, 86400, Parit Raja, \\ Batu Pahat, Johor, Malaysia \\ yuslinda89@gmail.com
}

Keywords: fine grained mortar, palm oil fuel ash, x-ray fluorescence, particle size analyzer, compressive strength, flexural strength

\begin{abstract}
This study was focusing on the utilization of Palm Oil Fuel Ash (POFA) and the effect of fine sand to develop the strength of the mortar. The flexural and compressive strength of fine grained mortar (FGM) with the addition of POFA and the sand usage with a size less than $1 \mathrm{~mm}$ were investigated. Then, the optimum percentage of POFA as a replacement material for cement was determined. Cement was partially replaced with POFA at various percentage of $0 \%$ to $40 \%$ by weight of cementitious materials with three (3) samples for each percentage. The laboratory test was conducted for this study are divided into two which are properties of samples (X-ray fluorescence and particle size analyzer), and hardened mortar (compressive and flexural strength). The prism specimens size are $40 \mathrm{~mm}$ x $40 \mathrm{~mm}$ x $160 \mathrm{~mm}$ and were tested at the age of 7 and 28 days according to BS EN 196-1:2005: Method of Testing Cement. The results showed that the highest flexural and compression strength is at $10 \%$ due to a factor which is the effect of POFA and fine sand produce a strong bond between the particles with the longer curing time, that is after 14 days. This is indicated that an additional of $10 \%$ POFA in FGM is the optimal percentage of POFA as a replacement for cement.
\end{abstract}

\section{Introduction}

A good quality of the mortar has high strength and durability. Fine particle size affects the performance of the mortar with a change in the air flow, compressive strength and mortar voids content [1]. These improvements can enhance the strength and durability and makes the structures and buildings constructed more attractive in surface structure [2]. Other than that, the utilization of materials such as ordinary portland cement (OPC) can cause the problem when carbon dioxide $\left(\mathrm{CO}_{2}\right)$ produced by the OPC can harm the environment [3]. So that, the solution to reduce the utilization of OPC is by replacing with the pozzolans material. Pozzolans material is a material that contains siliceous and aluminous materials and when mixed with water, it will react chemically with calcium hydroxide to produce cement property [4]. Based on previous researchers $[5,6,7,8]$, the studies on the suitability of industrial wastes such as Palm Oil Fuel Ash (POFA) which can be used as an alternative or as a supplement for cement that lead to global sustainable development and lowest possible environmental impact. POFA is produced from the combustion of palm oil mill effluent (POME) such as oil palm fibre, shells and a fruit bunch of empty at a temperature of $800^{\circ} \mathrm{C}-1000^{\circ} \mathrm{C}$ and has been used as a fuel for the electricity generation to increase the energy in palm oil mill [9]. Most of the POFA is disposed in landfills as a waste and become dangerous to the ecosystem [10]. From the combination of mortar quality and the effect of particle size, the POFA are used to replace the cement partially with the utilization of sand-size less than $1 \mathrm{~mm}$. In this study, an effort was made to evaluate the usefulness of fine grained mortar (FGM) containing POFA for producing the high strength mortar. The flexural and compressive strength were determined in order to get the optimum percentage of FGM. The application of FGM is necessary to improve the durability of mortar. 


\section{Materials and Methods}

Materials. The study was conducted using OPC and POFA that is obtained from palm oil mill located in Kluang, Johor. Firstly, to get the properties of sample the POFA was grinded by using ball mill grinder for 30 minutes with the speed of $350 \mathrm{rpm}$. Then, the POFA was sieved with size less than $45 \mu \mathrm{m}$ in order to get the $97 \%$ passing from the particle size analyzer (PSA) as shown in Fig 1. The amount of POFA used to replace OPC are $0 \%, 10 \%, 20 \%, 30 \%$ and $40 \%$. The OPC that used was a mixture of $0.15 \mathrm{~kg}$ for both the OPC and POFA. The three (3) samples were produced for each percentage. Fine aggregate (sand) was sieved according to the size less than that of $1 \mathrm{~mm}$ passing. The total amount of sand used was $0.45 \mathrm{~kg}$ for each sample. The superplasticizer (SP) was as much as $1 \%$ of cement to produce a sample with the same workability even with the low water content of the cement ratio [11].

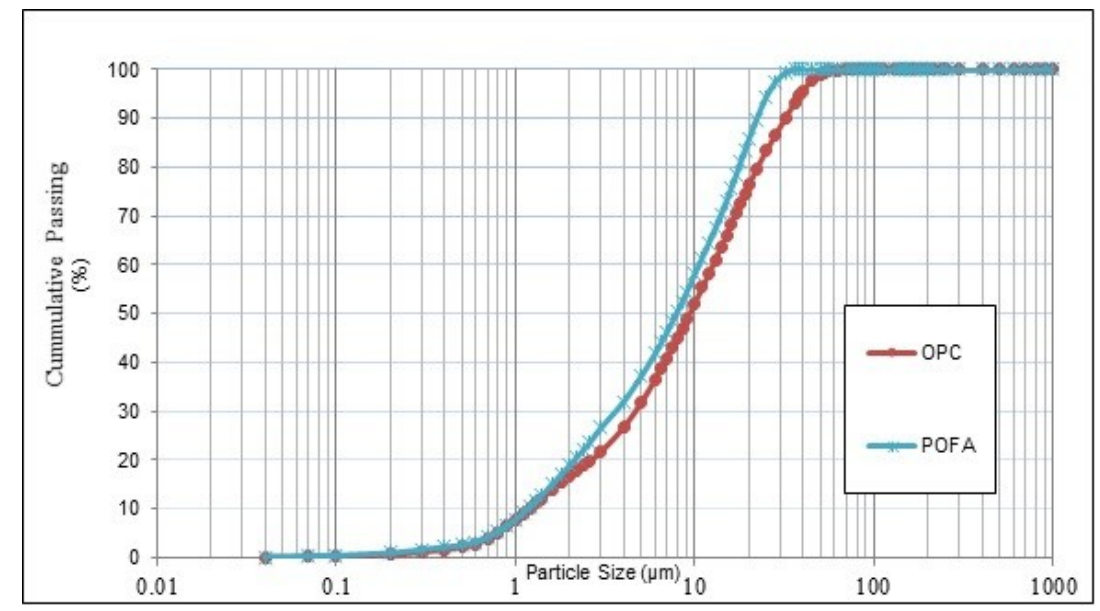

Fig. 1, Particle size distribution of POFA and OPC.

Mixture proportion. According to the BS EN 196-1 [11], a ratio of cementitious material (OPC + POFA) to sand was $1: 3$. The water binder ratio is 0.5 . The percentage flow of mortar was adjusted to $\pm 5 \%$ by mixing with water. The OPC was replaced by POFA at a percentages of $0 \%$ to $40 \%$ by weight of cementitious materials. Mortar were cast in $40 \mathrm{~mm}$ x $40 \mathrm{~mm}$ x $160 \mathrm{~mm}$ and was removed from moulds after casting for 24 hour. It was cured in water for 7 and 28 days [11]. All materials and mixture proportions of FGM for each sample are as shown in Table 1.

Table 1: Materials and mixture proportion

\begin{tabular}{|c|c|c|c|c|c|c|c|}
\hline Mix No. & Specimen & \multicolumn{3}{|c|}{ Binder $(\mathrm{g})$} & Fine Sand & Water & SP $(1 \%)$ \\
\hline & & OPC & Pozzolans & Total & $(\mathrm{g})$ & $(\mathrm{mL})$ & $(\mathrm{mL})$ \\
\hline 1 & Control & 150 & 0 & 150 & 450 & 75 & 1.5 \\
\hline 2 & POFA10 & 135 & 15 & 150 & 450 & 75 & 1.35 \\
\hline 3 & POFA20 & 120 & 30 & 150 & 450 & 75 & 1.2 \\
\hline 4 & POFA30 & 105 & 45 & 150 & 450 & 75 & 1.05 \\
\hline 5 & POFA40 & 90 & 60 & 150 & 450 & 75 & 0.9 \\
\hline
\end{tabular}

$* \mathrm{SP}=$ Superplasticizer

Compressive and flexural testing. The test was done according to the BS EN 196-1 [11]. The flexural strength testing use the methods for applying axial loading on three points bending. Meanwhile, the compression tests were made to determine the level of the FGM which is increased by age and by the continued strength. In general, this flexural and compressive testing is using bending machine bearing capacity and the load applied vertically. 


\section{Results and Discussions}

Characteristics of OPC and POFA. The chemical composition are as tabulated in Table 2. From the X-ray fluorescence (XRF) testing, the silica content of the POFA is $62.50 \%$ while the OPC is $16.40 \% . \mathrm{Al}_{2} \mathrm{O}_{3}$ content of OPC is $4.70 \%$ higher than that of POFA that is $4.68 \%$. The $\mathrm{CaO}$ content of POFA is relatively low at $7.7 \%$ compared to $69.6 \%$ of OPC. The others chemical components consisting of $\mathrm{Fe}_{2} \mathrm{O}_{3}, \mathrm{MgO}, \mathrm{SO}_{3}$ and $\mathrm{K}_{2} \mathrm{O}$ showed an insignificant difference between the OPC and POFA.

This is indicates that POFA has a high amount of silica content compared to OPC and it can be used in the construction industry as a cement replacement in order to avoid the carbon dioxide emissions that will pollute the environment $[6,12]$. According to the ASTM C618 [4], the value of $\mathrm{SiO}_{2}+\mathrm{Al}_{2} \mathrm{O}_{3}+\mathrm{Fe}_{2} \mathrm{O}_{3}$ of POFA that is $70.91 \%$ is closer to the required minimum of $70 \%$ of pozzolans. Also, this POFA is in class $\mathrm{F}$ because the value of $\mathrm{CaO}$ is less than $10 \%$.

Table 2: Chemical composition of POFA and OPC

\begin{tabular}{|lll|}
\hline Chemical composition (\%) & OPC & POFA \\
\hline $\mathrm{SiO}_{2}$ (Silicon dioxide) & 16.4 & 62.5 \\
$\mathrm{Al}_{2} \mathrm{O}_{3}$ (Aluminium oxide) & 4.7 & 4.68 \\
$\mathrm{Fe}_{2} \mathrm{O}_{3}$ (Ferric oxide) & 3.7 & 3.73 \\
$\mathrm{CaO}$ (Calcium oxide) & 69.6 & 7.7 \\
$\mathrm{MgO}$ (Magnesium oxide) & 1.22 & 3.69 \\
$\mathrm{~K}_{2} \mathrm{O}$ (Potassium oxide) & 0.67 & 9.0 \\
$\mathrm{SO}_{3}$ (Sulfur trioxide) & 2.65 & 2.06 \\
$\mathrm{LOI}^{\text {Loss of Ignition) }}$ & 2.2 & 6.5 \\
$\mathrm{SiO}_{2}+\mathrm{Al}_{2} \mathrm{O}_{3}+\mathrm{Fe}_{2} \mathrm{O}_{3}$ & 24.8 & 70.91 \\
\hline
\end{tabular}

Flexural and Compressive strength. The flexural and compressive strength results of FGM containing POFA are shown in Fig. 2 (a) and Fig. 2 (b) respectively. The results of flexural strength at the age of 7 days with a control mortar obtained the highest strength of $3.59 \mathrm{MPa}$. At the age of 28 days, the percentage of cement replaced with $10 \%$ POFA has the highest value of $4.62 \mathrm{MPa}$. Based on these results, the trend of compressive strength was similar with the flexural strength. The results of compressive strength at the age of 7 days shows the control mortar is at highest strength with the value of $28.13 \mathrm{MPa}$. At the age of 28 days, an additional $10 \%$ of POFA has the highest compressive strength with the value of $50.06 \mathrm{MPa}$.

This also indicates that 28 days is the optimum period for determination of the strength. The replacement of POFA at $10 \%$ gives the higher workability of FGM strength due to the fineness of POFA mixed with OPC to produce a strong bond between the particles and with the longer curing time that is after 14 days [8]. It is also due to the increasing in mortar microstructure that only happens through a pozzolanic reaction [6]. The pozzolanic reaction was occurred between the silica or lime and calcium hydroxide during the hydration of OPC. Then, it was produced calcium silica hydrate $(\mathrm{C}-\mathrm{S}-\mathrm{H})$ and calcium alumina hydrate which serves to cover up cracks and pores. It also reduce the permeability of the cement matrix $[2,13]$. 


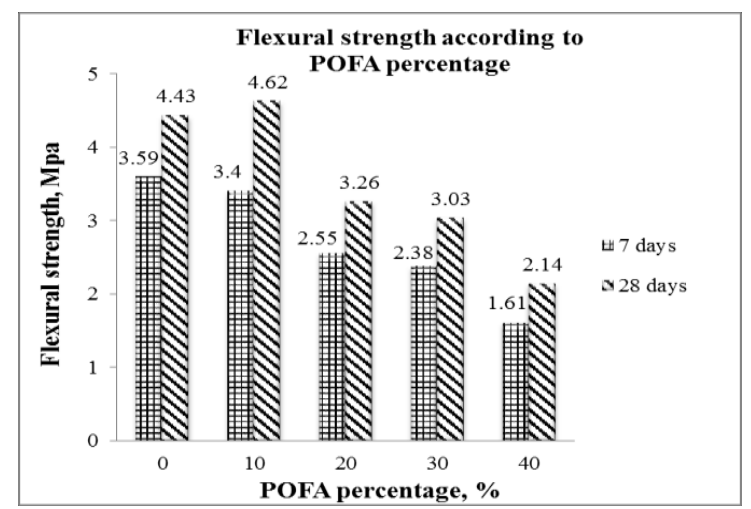

(a)

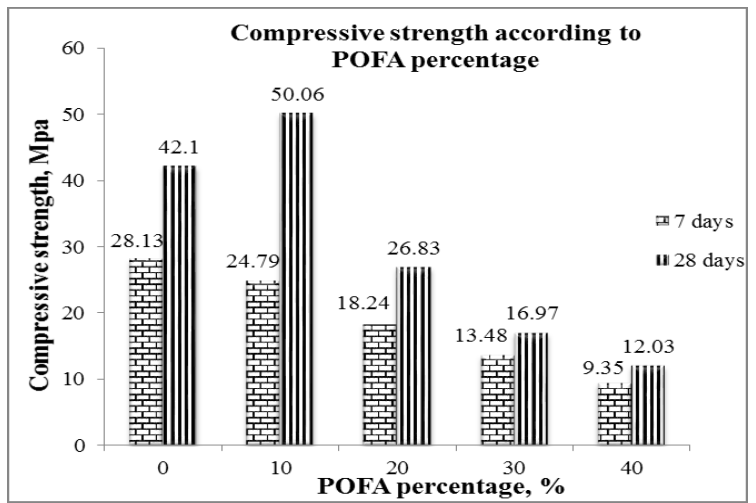

(b)

Fig. 2 (a) flexural strength (b) compressive strength according to POFA percentage.

Relationship between flexural and compressive strength. The relationship between flexural and compressive strength at the age of 7 and 28 days was shown in Fig. 3 (a) and Fig. 3 (b) respectively. From the figures, the relationship is decrease when the POFA content is increasing. This situation occurred due to the low cement content which is resulted in reduction of strength. Thus, calcium silicate hydrate gel are not produced due to the reduction of hydration agent [14]. At the early age, the control mortar was achieved the highest strength compared to additional of POFA in FGM. It was due to the slow formation of the pozzolanic reaction and generally starting after one or two weeks [2]. Mortar containing $10 \%$ to $40 \%$ of POFA starting to show pozzolanic reaction with a significant increase in strength for 28 days. Replacement of $10 \%$ POFA was observed at an early stage which shows the low strength and when reached the age of 28 days, a sudden change occurred when it achieved the higher percentage of mortar and thus the optimal percentage for the study.

Moreover, the relationship between the flexural and compressive strength can also be shown by $\mathrm{R}^{2}$ value which are 0.967 for 7 days and 0.9477 for 28 days respectively. Therefore, this relationship is used to determine the compressive strength and flexural strength in improving the study of FGM using POFA for longer curing age.

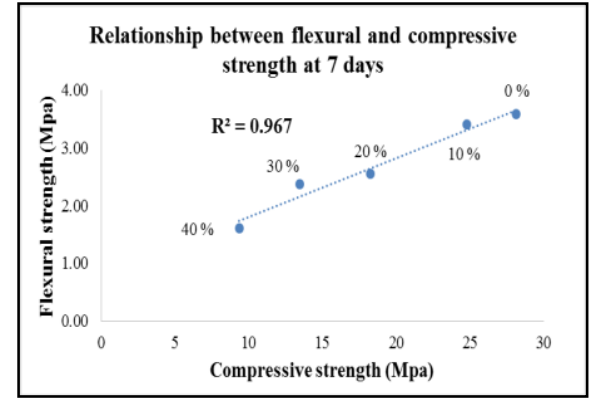

(a)

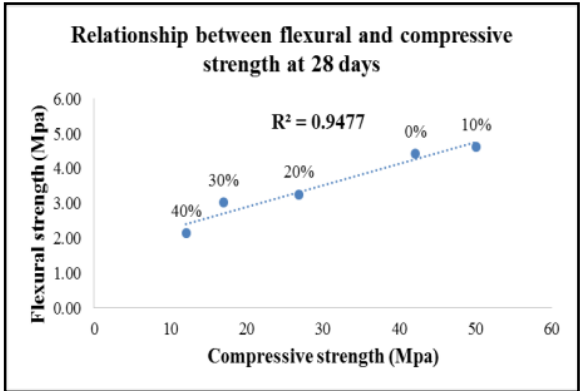

(b)

Fig. 3 Relationship between flexural and compressive strength for (a) 7 days (b) 28 days

\section{Conclusion}

From this study, it can be concluded that:

i) The addition of POFA by $10 \%$ to $40 \%$ as a partial cement replacement material can improve the flexural and compressive strength of FGM at 28 days. It occured when POFA are added to the mortar which will react after the age of 14 days. It also proves that the strength of FGM with the addition of POFA are better than that of the normal mortar. 
ii) The optimum percentage of flexural and compression strength is at additional of $10 \%$ of POFA because it cannot replace the conventional filler material as a whole and the use of hydrated lime was still required.

iii) The flexural and compressive strength were decrease when the addition of POFA up to $20 \%-40 \%$. If the POFA are fully replaced as a cement replacement material, it is unable to perform his functions as a binder.

\section{References}

[1] S. Tabata, S. Miyazato, T. Habuchi, T. Corporation, T. Amino, and H. Tanaka, Influence Of Fine-Grained Fraction Amount In Recycled Influence Of Fine-Grained Fraction Amount In Recycled, 2011.

[2] A. M. Neville, Properties of Concrete 5th edition, London: Pearson Education, 2011.

[3] C. Sujivorakul, Utilization of Fly Ash, Rice Husk Ash, and Palm Oil Fuel Ash in Glass Fiber-Reinforced Concrete, J. Mater. Civ., vol. 0, pp. 1281-1288, 2011.

[4] C. ASTM, 618, Standard Specification for Coal Fly Ash and Raw or Calcined Natural Pozzolan for Use in Concrete, ASTM Int., pp. 4-6, 2005.

[5] B. J. Tay, Ash From Oil - Palm Waste As Concrete Material, vol. 2, pp. 94-105, 1990.

[6] W. Kroehong and T. Sinsiri, Effect Of Palm Oil Fuel Ash Fineness On The Microstructure Of Blended Cement Paste, Build. Mater., vol. 25, pp. 4095-4104, 2011.

[7] M. W. Hussin, M. A. Ismail, A. Budiea, and K. Muthusamy, Durability Of High Strength Concrete Containing Palm Oil Fuel Ash Of Different Fineness, vol. 21, pp. 180-194, 2009.

[8] C. Jaturapitakkul, J. Tangpagasit, S. Songmue, and K. Kiattikomol, Filler Effect And Pozzolanic Reaction Of Ground Palm Oil Fuel Ash, Constr. Build. Mater., vol. 25, pp. 42874293, 2011.

[9] W. Tangchirapat, C. Jaturapitakkul, and P. Chindaprasirt, Use Of Palm Oil Fuel Ash As A Supplementary Cementitious Material For Producing High-Strength Concrete, Constr. Build. Mater., vol. 23, pp. 2641-2646, Jul. 2009.

[10] M. P. O. Board, Issues related to the Impact of Oil Palm on the Environment, pp. 1-3, 2014.

[11] B. EN, 196-1, Methods of testing cement, Determ. setting times soundness, vol. 3, 2005.

[12] N. M. Altwair, M. A. M. Johari, and S. F. S. Hashim, Flexural Performance Of Green Engineered Cementitious Composites Containing High Volume Of Palm Oil Fuel Ash, Constr. Build. Mater., vol. 37, pp. 518-525, 2012.

[13] W. Kroehong, T. Sinsiri, and C. Jaturapitakkul, Effect of Palm Oil Fuel Ash Fineness on Packing Effect and Pozzolanic Reaction of Blended Cement Paste, Procedia Eng., vol. 14, pp. 361-369, 2011.

[14] W. Tangchirapat and C. Jaturapitakkul, Cement \& Concrete Composites Strength , Drying Shrinkage, And Water Permeability Of Concrete Incorporating Ground Palm Oil Fuel Ash, Cem. Concr. Compos., vol. 32, no. 10, pp. 767-774, 2010. 